\title{
Toward a Unified Model for Contemporary Institutional Pharmacy Practice
}

\author{
James E Tisdale
}

W

hen a patient sees a physician anywhere in Canada or the United States, chances are high that the approach the physician takes to assessing and diagnosing actual or potential medical problems will be virtually the same as that of other physicians, regardless of geographic location or practice setting. Although different physicians may arrive at different diagnoses or different treatment plans for the same diagnosis, the process that they use to reach those decisions is consistent and essentially universal. This congruence reflects the fact that physicians have an established, consistent, widely accepted practice model. The same is true for dentists, as well as for the vast majority of other health care professionals.

On the other hand, when a patient is under the care of a hospital pharmacist in Canada or the United States, it is likely that the pharmacist's approach to assessing and diagnosing drug therapy problems will not be the same as and, in many cases, will not be remotely similar to that of other hospital pharmacists. The approaches of institutional pharmacists to the assessment and diagnosis of drug therapy problems and to the development of treatment plans vary widely from practitioner to practitioner, from institution to institution, and even from patient care unit to patient care unit within the same institution. Furthermore, chances are that the specific role of the pharmacist on the health care team will vary from institution to institution and from unit to unit. More broadly, specific drug distribution models, and the overall process of ensuring that the right patient receives the right drug at the right time, also vary widely from institution to institution, as do the roles assigned to pharmacy technicians. Even the technologies that we use in our drug distribution systems vary substantially from institution to institution. ${ }^{1,2}$ In brief, the profession of pharmacy, including pharmacy as practised in institutional settings, does not have an established, consistent, widely accepted practice model.

Why is this so? Why don't pharmacists have an established, consistent, widely accepted practice model? Part of the reason may be that the role of pharmacists within the health care system has not been precisely defined. I would propose that the role of the pharmacist, as an integral and indispensable member of collaborative multidisciplinary health care teams, is to identify, diagnose, and manage (or prevent) actual and potential drug therapy problems and to be responsible for patients' outcomes related to drug therapy. With respect to the drug distribution system, I see the role of the pharmacist as primarily that of an overseer, with technicians, using appropriate technology, being primarily responsible for functions within the system. However, my sense is

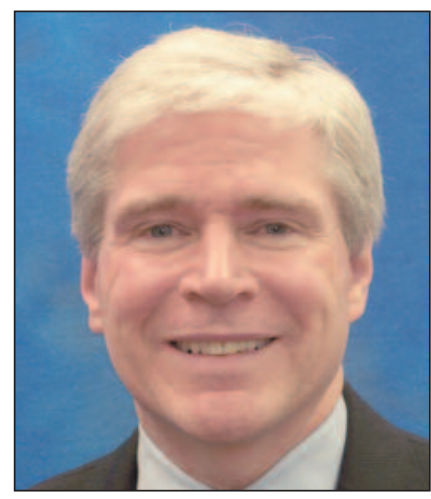
that many pharmacists and other health care professionals would not necessarily agree with me, and they might well propose a different definition of the pharmacist's role within the health care system. If we cannot define and agree upon our role, how can we delineate the appropriate practice model through which to fulfill that role?

Why is it important for medicine, dentistry, and, I would suggest, pharmacy, to have their own established, consistent, widely accepted practice models? Provided that each patient's drug therapy problems are adequately addressed, does it matter how the pharmacist achieved this? I would suggest that, without an established, consistently effective practice model, it is impossible to consistently and accurately identify, diagnose, and manage (or prevent) actual and potential drug therapy problems and thereby to improve patients' outcomes related to drug therapy. In pharmacy, we currently do not know which model of practice is most effective for improving patient outcomes, and this is a fertile area for pharmacy practice and comparative effectiveness research. An effective, consistent practice model would likely also help to establish and affirm the importance of pharmacists to patients and to the other health care professionals with whom we collaborate to deliver care, as it would more consistently demonstrate who we are, what we do, and why our work is important for patient care.

Pharmacy practice models, applicable to all pharmacists regardless of practice setting, have been proposed in the past. Most notably, the pharmaceutical care practice model was 
proposed by Cipolle and others in the 1990s. ${ }^{3}$ However, although this practice model received much attention and underwent substantial discussion, and while components of this model have been implemented by some, it has never been widely accepted or implemented in its full form by the majority of practitioners.

To a certain degree, practice change in hospital pharmacy is an aim of the Canadian Society of Hospital Pharmacists' 2015 initiative (CSHP 2015). ${ }^{4}$ The goals of CSHP 2015 include increasing the extent to which pharmacists help individual inpatients and outpatients to achieve the best use of medications, increasing the extent to which pharmacists in hospitals and related health care settings apply evidence-based methods to the improvement of medication therapy, advancing the role of hospital pharmacy departments in improving medication safety, improving the effectiveness of hospitals application of technology to improve medication safety, and increasing the engagement of hospital pharmacy departments in public health initiatives. However, although attainment of these goals may, at some institutions, be achieved by changing the practice model, CSHP 2015 does not specifically promote or advocate for the development of an established, consistent, widely accepted model of practice for hospital pharmacy.

Identification of an optimal model for contemporary institutional pharmacy practice is currently an issue of primary importance for the American Society of Health-System Pharmacists (ASHP) and its Foundation, which, in 2008, initiated development of the Pharmacy Practice Model Initiative (PPMI). The purpose of the PPMI is to "significantly advance the health and well being of patients by developing and disseminating a futuristic practice model that supports the most effective use of pharmacists as direct patient care providers." The practice model that is ultimately developed is intended to "reflect the evolution of numerous aspects of pharmacy practice in hospitals and health systems over the last 50 years", including medication-use policy and product selection, medication distribution, clinical pharmacy practice, roles of pharmacy technicians, roles of pharmacists as organizational leaders, adherence to standards-based practice, response to the medication-use quality and safety movements in the United States, and the impact of technology. ${ }^{6}$ The primary objectives of the PPMI are to create a framework for a pharmacy practice model that "ensures provision of safe, effective, efficient, accountable, and evidence-based care for all hospital/health system patients"; to determine the services that should consistently be provided by institutional departments of pharmacy; to identify emerging technologies to support implementation of the practice model; to develop a template for the practice model; and to implement specific action steps to achieve permanent change in the institutional pharmacy practice model. ${ }^{7}$

The initial component of the PPMI was a pharmacy practice model summit, held November 7 to 9, 2010, in Dallas, Texas. During the summit, over 100 thought leaders gathered to identify key outcomes related to the development of new practice models. ${ }^{5}$ Canadian hospital practice was represented by a practising Canadian hospital pharmacist and a representative from CSHP. Consensus was achieved on several specific ideas, including the following: changes are needed in the manner in which hospital pharmacists, technicians, and technology are deployed; pharmacy departments must be responsible for contributing to their respective hospitals' overall financial health; in the next 5-10 years, hospital executives will require greater efficiency from the operations component of pharmacy departments; routine sterile compounding functions can be assigned to pharmacy technicians with appropriate education and training; and pharmacists must perceive themselves as professionals and must act professionally at all times. ${ }^{5}$ Future steps in the PPMI include initiation of a social marketing campaign to broadly disseminate the proceedings and outcomes of the summit. In addition, grants for demonstration projects focusing on the influence of practice-model change on medication use will be offered by the ASHP Research and Education Foundation. ${ }^{8}$

Identification and implementation of a consistent, widely accepted practice model for pharmacy are worthy goals. How will development of a futuristic practice model that supports the most effective use of pharmacists as providers of direct patient care in the United States affect hospital pharmacy practice in Canada? That remains to be seen. Certainly, there are substantial differences in health care delivery between the 2 countries. However, despite those differences, the practice models employed by physicians and dentists in Canada and those of their counterparts in the United States are not appreciably different. There are opportunities for bold Canadian pharmacists and hospital pharmacy departments to experiment with new models of pharmacy practice and to conduct research comparing the effectiveness of various practice models. This is a chance for hospital pharmacy in North America to redefine itself, to define and assert the role of pharmacists on the health care team, and to establish a consistent, widely accepted practice model that ultimately improves patients' outcomes associated with medication therapy. If not now, when?

\section{References}

1. Bussières JF. Clinical pharmacy services. In: Babich M, Bussières JF, Hall KW, Harding J, Johnson N, Lefebvre P, et al., editors. 2007/08 hospital pharmacy in Canada report. Eli Lilly; 2008 [cited 2011 Jan 11]. p. 4-24. Available from: www.lillyhospitalsurvey.ca/hpc2/content/2008_report/ 2007_08_full.pdf

2. Harding J. Drug distribution systems. In: Babich M, Bussières JF, Hall KW, Harding J, Johnson N, Lefebvre P, et al., editors. 2007/08 hospital pharmacy in Canada report. Eli Lilly; 2008 [cited 2011 Jan 11]. p. 25-37. Available from: www.lillyhospitalsurvey.ca/hpc2/content/2008_report/2007_08_full.pdf

3. Cipolle RJ, Strand LM, Morley PC. Pharmaceutical care practice. New York (NY): McGraw-Hill; 1998.

4. CSHP 2015 goals and objectives. Ottawa (ON): Canadian Society of Hospital Pharmacists; 2007 [revised 2008 May 19; cited 2011 Jan 11]. Available from: www.cshp.ca/dms/dmsView/2_CSHP-2015-Goals-andObjectives-Feb-25\%2707-w-Appdx-rev-May\%2708.pdf

5. Thompson CA. Pharmacy Practice Model Initiative finishes consensusbuilding process. Am J Health Syst Pharm 2010;67(24):2078,2080,2082 
.6. Overview/rationale. In: Pharmacy Practice Model Initiative [website]. Bethesda (MD): American Society of Health-System Pharmacists; [cited 2011 Jan 11]. Available from: www.ashp.org/PPMI/AboutPPMI/ Overview.aspx

7. Objectives. In: Pharmacy Practice Model Initiative [website]. Bethesda (MD): American Society of Health-System Pharmacists; [cited 2011 Jan 11]. Available from: www.ashp.org/PPMI/AboutPPMI/Objectives.aspx

8. Activities. In: Pharmacy Practice Model Initiative [website]. Bethesda (MD): American Society of Health-System Pharmacists; [cited 2011 Jan 11]. Available from: www.ashp.org/PPMI/AboutPPMI/Activities.aspx
James E Tisdale, PharmD, is Professor, College of Pharmacy, Purdue University, and Adjunct Professor, School of Medicine, Indiana University, Indianapolis, Indiana. He is also an Associate Editor with the CJHP.

Address correspondence to:

Dr James E Tisdale

College of Pharmacy

Purdue University

W7555 Myers Building, WHS

1001 West 10th Street

Indianapolis IN 46202 USA

e-mail: jtisdale@iupui.edu

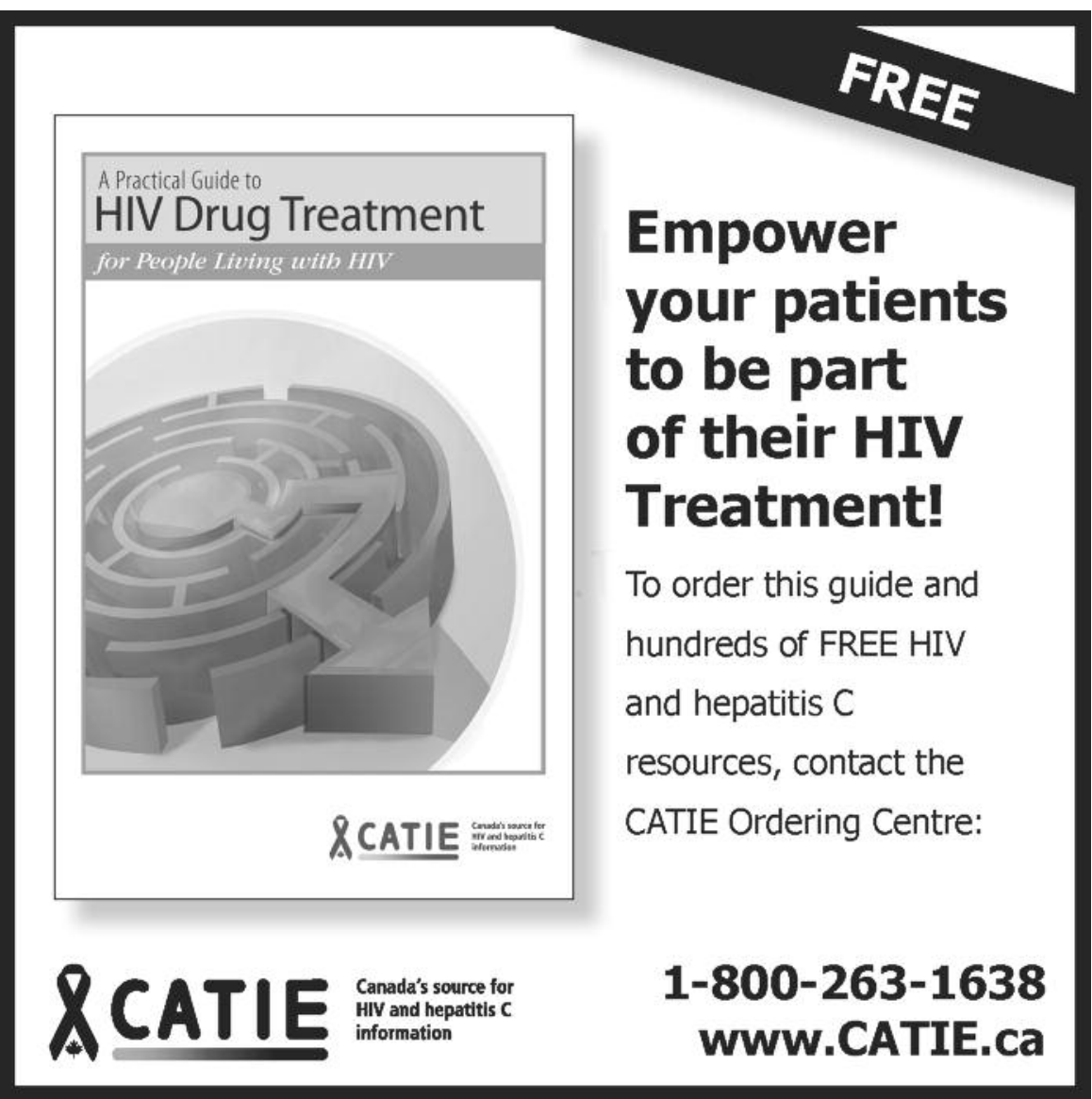

